\title{
Synthesis of Hydro-Sodalite as a Heterogeneous Catalyst for Reaction Kinetics of Soybean Oil Trans-Esterification
}

\author{
Márcia Cardoso Manique*, Luciane Venturini Lacerda, Annelise Kopp Alves and Carlos Pérez Bergmann \\ Laboratory of Ceramic Materials (LACER), School of Engineering, Federal University of Rio Grande do Sul (UFRGS), 90035-190, Porto Alegre, RS, Brazil
}

\begin{abstract}
A kinetic study evaluating heterogeneous transesterification of soybean oil was performed using zeolite from coal fly ash as a catalyst, under reaction conditions with different temperatures and reaction times. The catalyst characterization revealed that zeolite type hydro-sodalite was synthesized and consists of mesoporous agglomerates particles with a specific surface area of $7.53 \mathrm{~m}^{2} \mathrm{~g}^{-1}$ and a basic catalytic character. The conversion rate of soybean oil to its methyl esters was found to increase with an increase in temperature. An ester yield of $92.5 \%$ was the highest methyl ester achieved at $65^{\circ} \mathrm{C}$ and at a $12: 1$ methanol-to-oil molar ratio. The reaction followed pseudo-first order kinetics with a calculated activation energy $\left(E_{a}\right)$ of $27.23 \mathrm{~kJ} \mathrm{~mol}^{-1}$.
\end{abstract}

Keywords: Hydro-sodalite; Heterogeneous catalysis; Transesterification; Biodiesel; Kinetics

\section{Introduction}

Global trends point towards reduced dependence on fossil fuels, and increasing environmental awareness has motivated the search for biodiesel fuels capable of replacing petroleum diesel [1-3]. Biodiesel is a mono alkyl ester of fatty acids produced from vegetable oils or animal fats; it is environmentally friendly and can be used as an alternative to fossil fuels $[2,4]$. Biodiesel has various important characteristics such as non-toxicity, biodegradability, high energy content, and sulfur-free compositions $[5,6]$.

The primary chemical process used in biodiesel production is alkaline transesterification with methanol and potassium hydroxide $(\mathrm{KOH})$ wherein alcohol reacts, in the presence of a catalyst, to form alkyl esters (biodiesel) and glycerin (Figure 1a) $[2,7,8]$. This process can produce yields of $97-99 \%$ in $0.5-1 \mathrm{~h}[9,10]$. However, the homogeneous base catalysis process has some disadvantages such as consumption of the catalyst, which cannot be regenerated. In addition, recovery of glycerol is difficult because of the surfactant effect of the fatty acid salts formed; saponification is sensitive to the presence of free fatty acids and water [10-12]. The substitution of homogeneous for heterogeneous catalysts can solve these problems. These advantages include the ease with which catalysts are separated from solution and the consequent ability to reuse the catalyst in downstream chemistry [13,14]. Singh and Fernando [15] studied soybean oil transesterification using metal oxide heterogeneous catalysts and obtained a conversion level of $99 \%$ at a reaction temperature of $215^{\circ} \mathrm{C}$ under high pressure. TalebianKiakalaieh et al. [4] used heteropoly acids for the transesterification of used cooking oil and reported $88.6 \%$ conversion at $65^{\circ} \mathrm{C}$, with a methanol-to-oil molar ratio of 70:1 and $10 \mathrm{wt} \%$ catalyst. The objectives are higher product yields and higher purity in the development of a new catalyst, and to avoid high cost production, a high reaction temperature, and a long reaction time.

Zeolites are microporous crystalline aluminosilicates that possess molecular shape selective properties. The synthesis is completed by aluminum and silicon precursors, which are the structural elements of zeolites [16]. Because coal fly ash-a by-product of coal-based thermal power plants-is composed largely of silica-aluminum, it can be easily converted into zeolite via a hydrothermal treatment in an alkaline solution [17]. Such a treatment process can lead to the formation of various types of zeolites under different reaction conditions such as varying temperature, alkaline reagent concentration, reaction time, and solution/fly ash ratio [16]. Zeolites have shown promising results as catalysts in the transesterification of refined and waste oils [10$12,18-20]$. However, a few studies have reported the chemical kinetics of transesterification with zeolite as a catalyst.

The kinetics of a process describes its rate of chemical reaction. Freedman et al. [21] reported a study for the transesterification of soybean oil using sodium hydroxide as a homogeneous catalyst. In this work, they assumed that transesterification is a three-step reaction: initially the triglyceride molecules are converted into diglycerides, then into monoglycerides, and finally into glycerin. This produces one mole of ester at each reaction stage (Figure $1 \mathrm{~b}$ ). It was found that the reactions appear to be second order for a butanol/oil molar ratio of 6:1 and pseudo-first order for butanol/oil molar ratio of 30:1. The reverse reactions appeared to be second order. At a methanol/oil molar ratio of 6:1, a shunt reaction was observed. The activation energy was obtained from the linearization of the Arrhenius equation by constructing a graph of $\ln k$ (rate constant) versus the inverse of the temperature.

Based on these considerations, the aim of this study was to investigate the catalytic performance of the zeolite in the transesterification of soybean oil with methanol in different temperatures and to calculate the kinetic parameters, including the activation energy.

\section{Materials and Methods}

\section{Materials}

Coal fly ash samples were collected from a Brazilian thermal power plant (Candiota Thermal Power Station). Solvents and other reagents were of analytical grade (Merck or similar). The chromatographic

*Corresponding author: Márcia Cardoso Manique, Laboratory of Ceramic Materials (LACER), School of Engineering, Federal University of Rio Grande do Sul (UFRGS), 90035-190, Porto Alegre, RS, Brazil, Tel: +55 51 33083637; Fax: +55 51 33083405; E-mail: marciamanique@yahoo.com.br

Received November 07, 2018; Accepted December 15, 2018; Published December 25, 2018

Citation: Manique MC, Lacerda LV, Alves AK, Bergmann CP (2018) Synthesis of Hydro-Sodalite as a Heterogeneous Catalyst for Reaction Kinetics of Soybean Oil Trans-Esterification. J Material Sci Eng 7: 500. doi: 10.4172/2169-0022.1000500

Copyright: (c) 2018 Manique MC, et al. This is an open-access article distributed under the terms of the Creative Commons Attribution License, which permits unrestricted use, distribution, and reproduction in any medium, provided the original author and source are credited. 
(a)

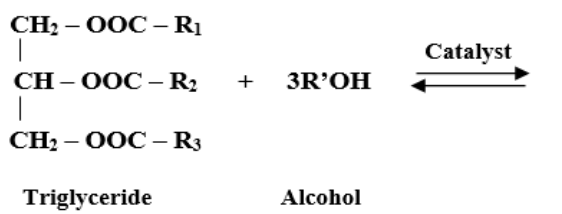

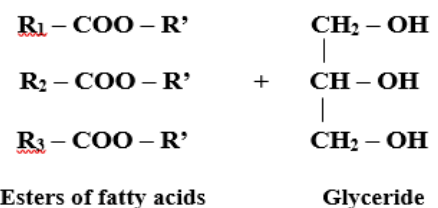

Esters of fatty acids Glyceride

\section{Triglyceride $+\mathrm{R}$ 'OH
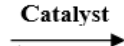 \\ Catalyst \\ 2. Diglyceride + R'OH \\ Diglyceride + R'COOR \\ Monoglyceride+ R'COOR 2 \\ 3. Monoglyceride + R'OH \\ Catalyst \\ Glyceride + R'COOR}

Figure 1: Transesterification of triglyceride with alcohol. (A) General equation; (B) Three consecutive and reversible reactions. $R_{1}, R_{2}$, $R_{3}$, and R' are alkyl groups.

standards were acquired from Sigma-Aldrich. The gases used in the chromatographic analyses $\left(\mathrm{H}_{2}, \mathrm{~N}_{2}\right.$, and synthetic air with a purity exceeding 99.999\%) were purchased from White Martins. Edible soybean oil was purchased from a local market (acid number $=0.05 \mathrm{mg}$ $\left.\mathrm{KOH} \mathrm{g}^{-1}\right)$.

\section{Zeolite synthesis from coal fly ash}

The synthesis of zeolite using coal fly ash was described in a previously study [20] using a method adapted from Petkowicz et al. [22]. Briefly, $1.65 \mathrm{~g}$ of aluminate sodium $\left(\mathrm{NaAlO}_{2}\right), 1.17 \mathrm{~g}$ of $\mathrm{NaOH}, 1.3$ $\mathrm{mL}$ of deionized water, and $0.89 \mathrm{~g}$ of coal fly ash were added to form a sticky gel that was stirred for 15 min until complete homogenization. The aging period was 6 days. After crystallization for $24 \mathrm{~h}$ at $100^{\circ} \mathrm{C}$, the mixture was washed with deionized water until $\mathrm{pH}$ of 9 was achieved. Finally, the solid material was dried at $100^{\circ} \mathrm{C}$ for $24 \mathrm{~h}$. The Si-to-Al molar ratio for the sample was calculated to be 1 .

\section{Characterization of the catalyst}

The X-ray Diffraction (XRD) analyses were carried out using a PHILIPS X-ray diffractometer (model X'PERT MDP) with Ni-filtered $\mathrm{Cu} \mathrm{Ka}$ radiation at $15.418 \mathrm{~nm}$ in the $2 \theta$ range from $5-45^{\circ}$. Chemical bonding information was obtained using a Fourier transform infrared spectrometer (FTIR Shimadzu IRAffinity-1) with KBr pellets from 4000 to $600 \mathrm{~cm}^{-1}$. The morphology of the sample was analyzed by scanning electron microscopy (SEM) using a JEOL JSM 6060 instrument. The specific area and pore size distribution were measured by adsorptiondesorption isotherms $\left(\mathrm{N}_{2}\right)$ at $77 \mathrm{~K}$ using BET (Brunauer, Emmett and Teller) and $\mathrm{BJH}$ (Barret, Joyner and Hallenda) methods, respectively. The analysis was performed using a Quantachrome Nova 1000e.

\section{Biodiesel production by heterogeneous transesterification}

Transesterification reactions were carried out in a $100 \mathrm{~mL}$ flask equipped with a condenser. Known masses of soybean oil were transferred to the flask and heated in the programed temperature with continuous stirring at $300 \mathrm{rpm}$. Then, methanol and the catalyst were added to the oil to start the reaction. The total reaction time was $1 \mathrm{~h}$. Experiments with different reaction temperatures $\left(35^{\circ} \mathrm{C}, 50^{\circ} \mathrm{C}\right.$ and $65^{\circ} \mathrm{C}$ ) were performed. Aliquots were collected from the reaction mixture at specified times during the progress of the reaction. The best condition obtained in the previous study [20] was used: methanol/oil molar ratio of $12: 1$ and a catalyst quantity of $4 \mathrm{wt} \%$.

\section{Characterization of biodiesel}

The analysis of biodiesel conversion was conducted in a gas chromatograph (7820A; Agilent) using a flame ionization detector (FID) equipped with a HP-5 5\% phenyl-methylpolysiloxane $(30 \mathrm{~m}$ $\times 0.25 \mathrm{~mm} \times 0.25 \mu \mathrm{m})$ column. Hexane was used as the solvent, and the carrier was gas nitrogen at a flow rate of $1 \mathrm{~mL} / \mathrm{min}$. A solution of ethyl palmitate $(10 \mathrm{mg} / \mathrm{mL})$ was used as the internal standard. The temperature program was as follows: $120^{\circ} \mathrm{C}$ for $2 \mathrm{~min}$, heating up to $250^{\circ} \mathrm{C}$ at a rate of $8^{\circ} \mathrm{C} / \mathrm{min}$ and holding at $250^{\circ} \mathrm{C}$ for $10 \mathrm{~min}$. The injector and the detector were set for $250^{\circ} \mathrm{C}$; the injection volume was $1 \mu \mathrm{L}$.

\section{Results and Discussion}

\section{Characterization of the zeolite}

Figure 2 shows the results of X-ray diffraction for the zeolite synthesized via the hydrothermal method. According to the XRD patterns, the prominent peaks at $14.1^{\circ}, 24.5^{\circ}, 31.8^{\circ}, 35.0^{\circ}, 37.9^{\circ}$, and $43.2^{\circ}$ match the characteristic peaks of SOD zeolite. Moreover, the quartz and mullite from the coal ash that was not fully converted was also identified. The low solubility of the quartz and mullite at a low temperature can explain this behavior.

The FTIR transmittance spectra of zeolite are presented in Figure 3. A broad peak at about $3400 \mathrm{~cm}^{-1}$ is assigned to the stretching vibration mode of the $\mathrm{O}-\mathrm{H}$ groups attributed to the surface adsorbed water molecule, and a corresponding bending mode at near $1640 \mathrm{~cm}^{-1}$ was also observed from $\mathrm{O}-\mathrm{H}$ groups [17]. Meanwhile, the most relevant band is observed in the $950 \mathrm{~cm}^{-1}$ corresponding to an intense $\mathrm{Si}(\mathrm{Al})-\mathrm{O}$ band [23]. The characteristic FTIR vibration bands of the hydro-sodalite materials are as follows: $1400 \mathrm{~cm}^{-1}-$ asymmetric stretching $(\mathrm{O}-\mathrm{Al}-\mathrm{O})$; $860 \mathrm{~cm}^{-1}$ - symmetric stretching ( $\left.\mathrm{Si}-\mathrm{O}-\mathrm{Si}\right) ; 655 \mathrm{~cm}^{-1}$ and $620 \mathrm{~cm}^{-1}$. symmetric stretching ( $\mathrm{Si}-\mathrm{O}-\mathrm{Si}$ and $\mathrm{Al}-\mathrm{O}-\mathrm{Si})[17,23,24]$. The oxygen atom in the $\mathrm{Si}-\mathrm{O}-\mathrm{Al}$ species bears a negative charge that may generate a basic character. The basicity may also originate from other sites like basic hydroxyls, encaged oxide clusters, supported metals, or reducing centers [25]. Thus, hydro-sodalite can be classified as a basic catalyst associated with $\mathrm{Si}-\mathrm{Al}$ systems. 


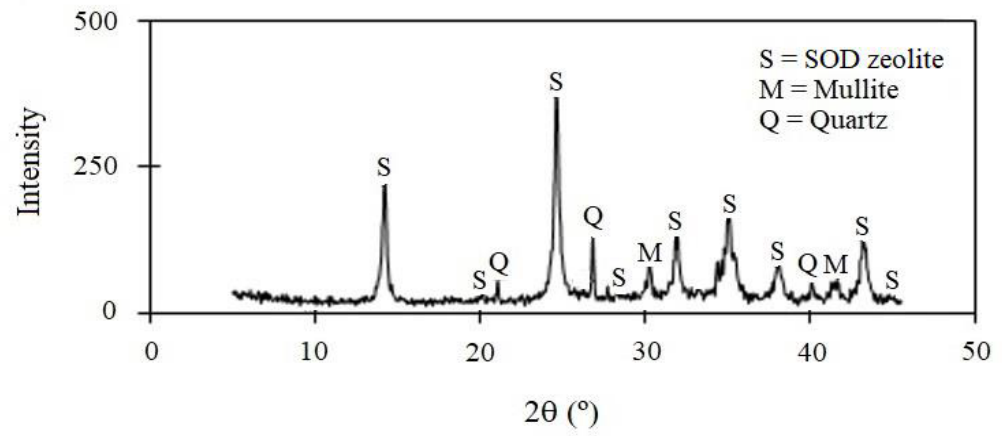

Figure 2: XRD patterns of zeolite.

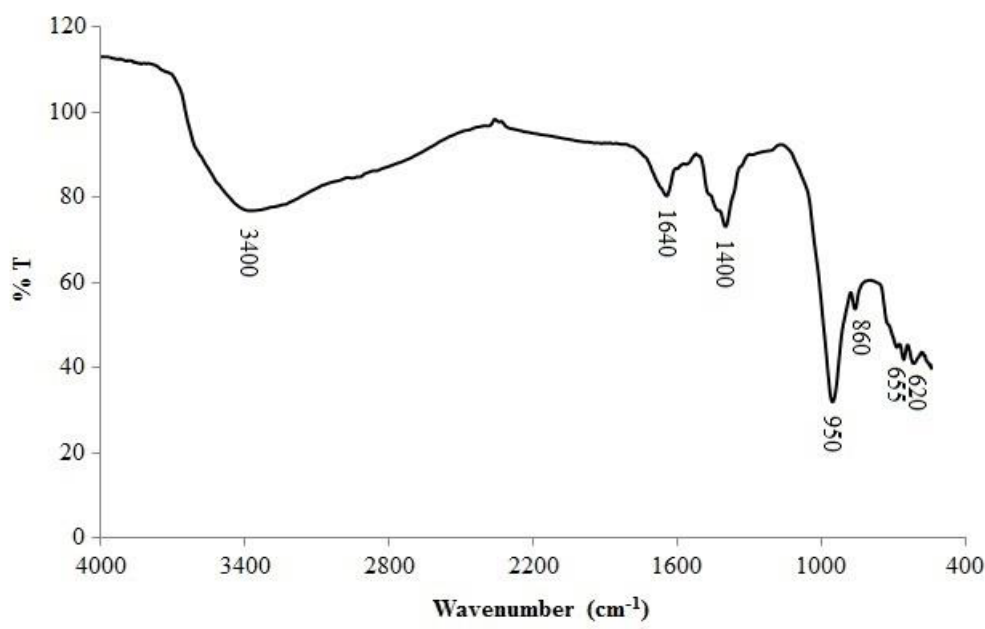

Figure 3: FTIR spectra of hydro-sodalite.

Figure 4 shows the $\mathrm{N}_{2}$ adsorption-desorption isotherm for the synthesized hydro-sodalite, and the inset is the BJH plot (pore size distribution). These data reveal that the hydro-sodalite has a typical type-IV isotherm that is characteristic of mesoporous materials. In addition, the hysteresis loop shifted at $\mathrm{P} / \mathrm{Po} 0.5$ values, which indicates the presence of small to medium mesopores in the sample. This was confirmed by the corresponding pore-size distribution. The hierarchical porous structures consist of mesopores in the pore size range of 3-20 $\mathrm{nm}$. Hysteresis loops can be classified as H4 Type and are characterized by the presence of narrow slit-like pores [26]. The $\mathrm{N}_{2}$ adsorption-desorption isotherms were used to measure the specific area and the pore volume of hydro-sodalite to be $7.53 \mathrm{~m}^{2} \mathrm{~g}^{-1}$ and 0.03 $\mathrm{cm}^{3} \mathrm{~g}^{-1}$, respectively.

Figure 5 shows the morphology of the hydro-sodalite derived from the coal fly ash in a different approximation. The synthesized zeolite appears as crystals deposited on the surface of the fly ash particles during hydrothermal treatment. The crystalline growth may have been hindered by the presence of an uneven surface (smaller crystallites) that can be justified by the presence of impurities in the ash, which led to rapid nucleation. Particle aggregation explains the formation of textural mesoporosity as shown in the $\mathrm{N}_{2}$ adsorption-desorption isotherm.

\section{Biodiesel production and kinetic approach}

The effect of reaction temperature on transesterification reaction

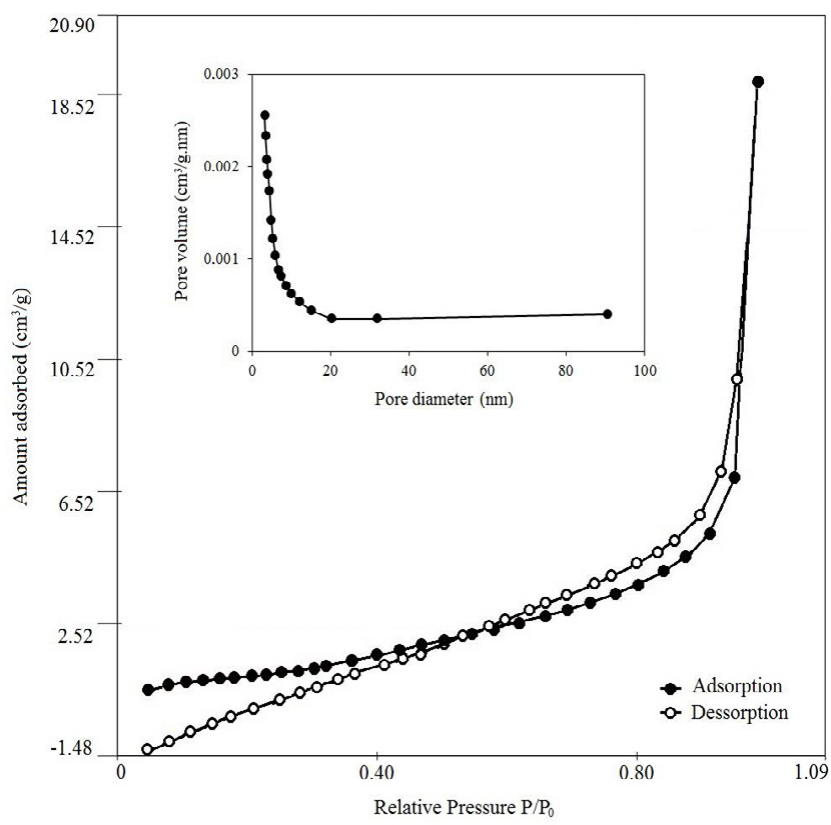

Figure 4: $\mathrm{N}_{2}$ adsorption-desorption isotherms for hydro-sodalite. Inset: pore volume distribution of hydro-sodalite. 


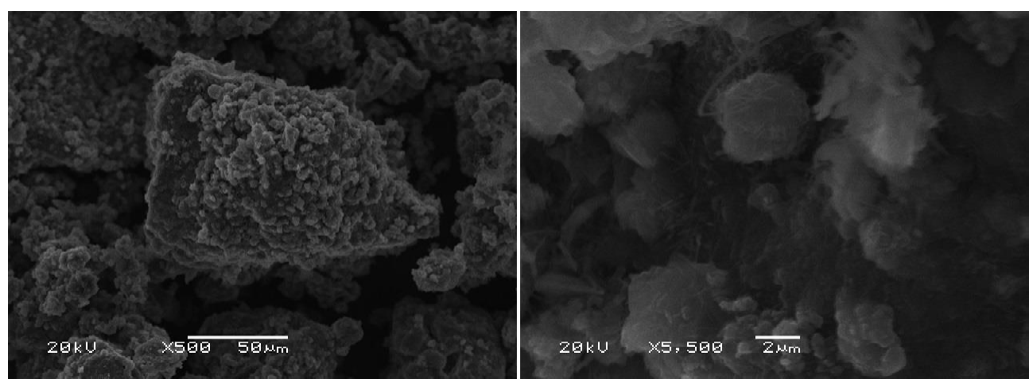

Figure 5: SEM micrographs of hydro-sodalite.

was carried out in different temperatures ranging from $35^{\circ} \mathrm{C}$ to $65^{\circ} \mathrm{C}$ to identify the influence on reaction conversion. Figure 6 shows that the conversion increased as the temperature increased with values of $90.2 \%$ at $35^{\circ} \mathrm{C}, 91.3 \%$ at $50^{\circ} \mathrm{C}$ and $92.5 \%$ at $65^{\circ} \mathrm{C}$. These results agree with other studies $[3,4,12]$. The conversion difference as a function of temperature was not dramatic suggesting that all the temperatures tested can be used for biodiesel production with hydro-sodalite as catalyst. Furthermore, the reaction progressed rapidly during the first 15 min to yield a conversion of $87 \mathrm{wt} \%$ of methyl ester following a similar conversion to homogeneous base catalyst.

Kinetic studies have been carried out at the optimum conditions of 12:1 methanol to oil molar ratio, and 4 wt\% hydro-sodalite as the catalyst in a reaction time of $15 \mathrm{~min}$. As mentioned above, the transesterification is a reversible reaction; therefore, excess methanol is used to drive the reaction forward. Eq. (1) shows the generalized transesterification reaction.

$$
\mathrm{A}+3 \mathrm{~B} \Leftrightarrow \mathrm{C}+\mathrm{D}
$$

where $A$ is the triglyceride, $B$ is methanol, $C$ is methyl esters, and $D$ is glycerol. Based on a previously reported mechanistic consideration $[4,15,27,28]$, the general rate equation for the eqn. (1) is:

$$
\frac{-\mathrm{d} C_{A}}{\mathrm{~d} t}=k C_{A}{ }^{\alpha} C_{B}{ }^{\beta}-k^{\prime} C_{C}^{\gamma} C_{D}{ }^{\lambda}
$$

where $C_{A}, C_{B}, C_{C}$, and $C_{D}$ are the concentrations of triglyceride, methanol, methyl esters, and glycerol, respectively. Here, $\alpha, \beta, \gamma$ and $\lambda$ are their respective reaction orders; $k$ is the kinetic constant for the forward reaction, and $k$ ' is the kinetic constant for the reverse reaction.

Suppose that the original molar ratio of methanol and triglyceride is 3:1. An excess of methanol was used to push the equilibrium to the formation of methyl esters. Thus, the expression of methanol $\left(C_{B}^{\beta}\right)$ can be treated as a constant. Therefore, the kinetic constant for forward reaction $(k)$ outweighs the kinetic constant for reverse reaction $\left(k^{\prime}\right)$. Therefore, eqn. (2) has been reduced to:

$$
\frac{-\mathrm{d} C_{A}}{\mathrm{~d} t}=k_{1} C_{A}{ }^{\eta}
$$

where $k_{1}=k C_{B}^{\beta}$ is modified reaction kinetic constant. In addition:

$$
C_{A}=C_{A 0}(1-X)
$$

where $C_{A 0}$ is the initial concentration of triglycerides, and $X$ is the conversion of methyl esters (biodiesel). Therefore, the overall reaction rate can be expressed via the following equation:

$$
\frac{\mathrm{d} X}{\mathrm{~d} t}=\frac{k_{1}}{C_{A 0}}\left[C_{A 0}(1-X)\right]^{n}=k_{2}\left[C_{A 0}(1-X)\right]^{n}
$$

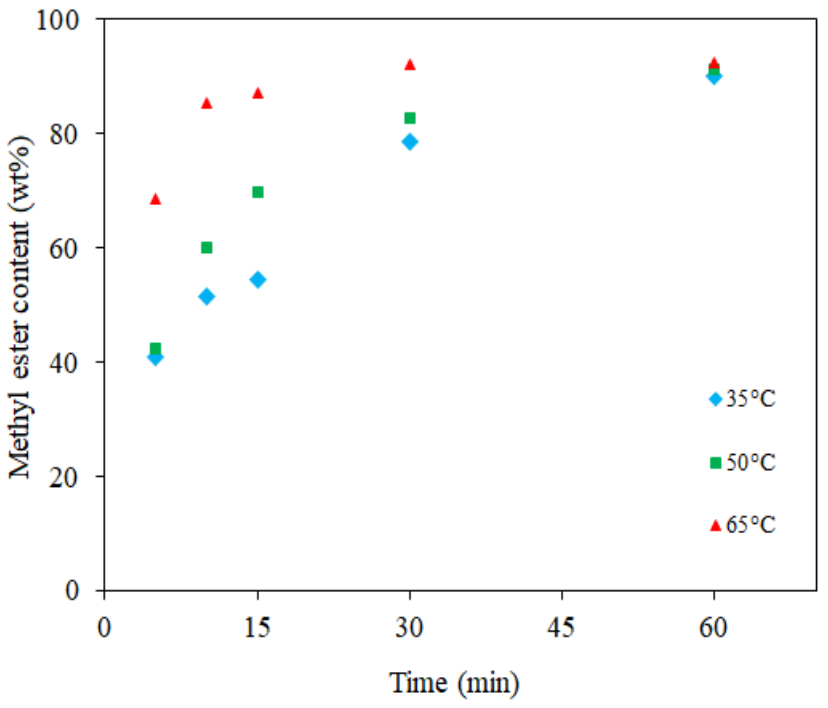

Figure 6: Transesterification reaction results as a function of reaction temperature and reaction time (4 $\mathrm{wt} \%$ sodalite and 12:1 methanol to oil molar ratio).

where $k_{2}=k_{1} / C_{A 0}$. When $n=1$, Eq. (5) can be integrated to obtain the following equation:

$$
\ln (1-X)=-k_{1 t}
$$

The reaction conversion at different temperatures and time intervals shown in Figure 6 is necessary to calculate the kinetic parameters including the kinetic rate constant and the activation energy. Thereafter, the order of the reaction can be determined by substituting the conversions into eqn. (6). Figure 7 shows the linear relationship between $\ln (1-X)$ versus time $(t)$, and this demonstrated that the transesterification reaction had first order kinetics. Considering that a high methanol-to-oil molar ratio was used in the reactions, the change in methanol concentration can be considered to be constant. Therefore, the reaction is predicted to be a pseudo-first order reaction.

The reaction kinetic constant $\left(k_{1}\right)$ for respective temperatures can be determined based on eqn. (6). Table 1 tabulates the calculated reaction kinetic constants at different temperatures. There was an increasing trend of reaction kinetic constants with increasing reaction temperature. This means that with increasing temperature, the reaction favors the conversion of methyl esters, which increases their concentration as well as $k_{1}$, which is directly proportional.

Kinetic constants were then used to find the activation energy 


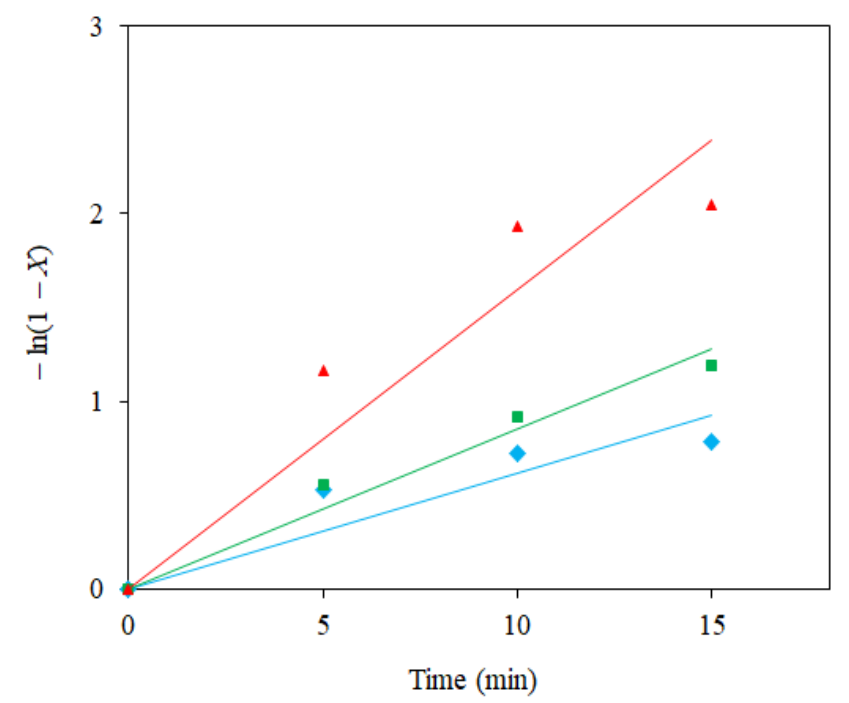

Figure 7: Relationship of $-\ln (1-X)$ with time $(t)$ fitted with the reaction results of the transesterification.

\begin{tabular}{|c|c|}
\hline Temperature $\left({ }^{\circ} \mathbf{C}\right)$ & $\boldsymbol{k}_{\mathbf{1}}\left(\mathbf{m i n}^{-1}\right)$ \\
\hline 35 & 0.0617 \\
\hline 50 & 0.0853 \\
\hline 65 & 0.1594 \\
\hline
\end{tabular}

Table 1: Reaction kinetic constants estimated at different temperatures.

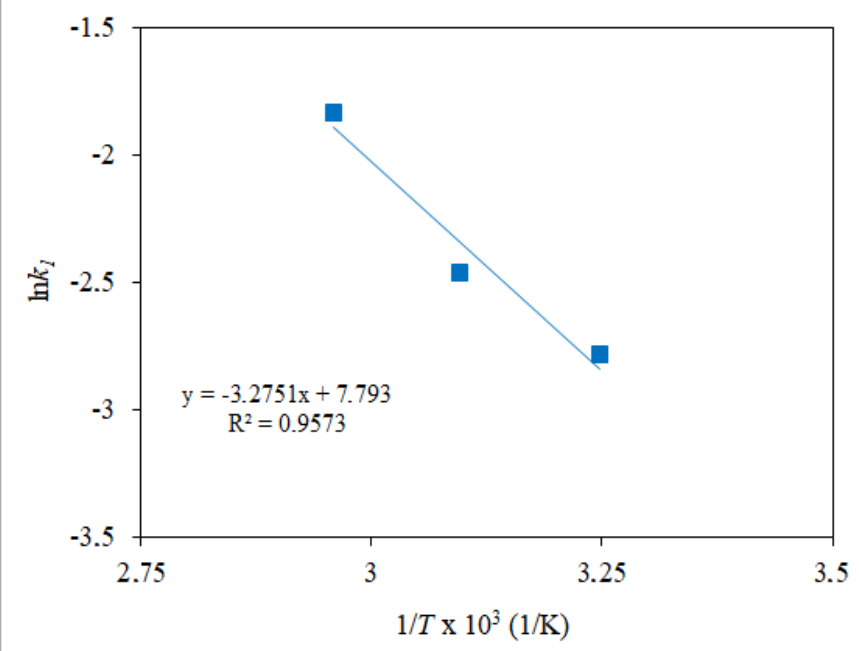

Figure 8: Arrhenius plot of Ink versus $1 / T$ for transesterification reaction.

$\left(E_{a}\right)$ and the pre-exponential factor $(A)$ for the reaction based on the Arrhenius equation:

$$
\ln k_{1}=\frac{-E_{a}}{R T}+\ln A
$$

Figure 8 shows the plot of the constants from the linear equation $\ln k_{1}$ versus $1 / T$ based on the Arrhenius equation (eqn. (7)). The slope and intercept of this graph indicated the values of $E_{a}$ and $A$ from the Arrhenius equation. The activation energy and the pre-exponential factor were $27.23 \mathrm{~kJ} \mathrm{~mol}^{-1}$ and $2423.58 \mathrm{~min}^{-1}$, respectively. These values were compared to previous results focusing on a kinetic study

\begin{tabular}{|c|c|c|}
\hline Catalyst & $\boldsymbol{E}_{\mathbf{a}}\left(\mathbf{k J} \mathbf{~ m o l}^{-1}\right)$ & References \\
\hline $\mathrm{H}_{2} \mathrm{SO}_{4}$ and $\mathrm{NaOBu}$ & $33.6-84$ & {$[21]$} \\
\hline $\mathrm{Ca}\left(\mathrm{OCH}_{3}\right)_{2}$ & 71.25 & {$[29]$} \\
\hline $\mathrm{La}_{2} \mathrm{O}_{3}$ & 44.41 & {$[30]$} \\
\hline Zeolite LTA & 14.09 & {$[31]$} \\
\hline
\end{tabular}

Table 2: Activation energy $\left(E_{a}\right)$ obtained for soybean oil transesterification.

for soybean oil transesterification collected in Table 2. The activation energy in this study was comparatively lower than those reported either with homogeneous or heterogeneous catalysts $[21,29,30]$. The activation energy obtained here $\left(27.23 \mathrm{~kJ} \mathrm{~mol}^{-1}\right)$ approached the value by Dang et al. [31] who used zeolite LTA as a catalyst $\left(14.09 \mathrm{~kJ} \mathrm{~mol}^{-1}\right)$. These results using zeolites in the transesterification reactions show lower energy needs. Similar to Kirumakki et al. [32], the mechanism of the zeolite reaction is attributed to their basic or acid site strengths and distribution. There is no evidence of pore size involvement. Thus, the lower energy and the structural properties show the potential of hydrosodalite in the transesterification of soybean oil.

\section{Conclusions}

Analyses revealed the synthesis of hydro-sodalite from coal fly ash that has a basic character, which offers high catalytic performance for biodiesel production. The highest methyl ester yield of $92.5 \%$ was achieved at $65^{\circ} \mathrm{C}$ for $1 \mathrm{~h}$ under the following reaction conditions: 35 $65^{\circ} \mathrm{C} ; 12: 1$ methanol to oil molar ratio; and $4 \mathrm{wt} \%$ catalyst loading. A pseudo-first order reaction was established by fitting the kinetic model to the experimental results. The activation energy from a transesterification reaction of soybean oil was $27.23 \mathrm{~kJ} \mathrm{~mol}^{-1}$. These conditions demonstrate the strong potential of zeolite hydro-sodalite as a low-price product to be used as a heterogeneous catalyst on an industrial scale.

\section{Acknowledgment}

We would like to express our gratitude and indebtedness to the Biocatalysis Laboratory (UFSC) for providing the GC-FID facilities. We would like to thank CNPq for its financial support.

\section{References}

1. Alenezi R, Santos RCD, Raymahasay S, Leeke GA (2013) Improved biodiesel manufacture at low temperature and short reaction time. Renew Energy 53: 242-248.

2. Marchetti JM, Errazu AF (2008) Comparison of different heterogeneous catalysts and different alcohols for the esterification reaction of oleic acid. Fuel 87: 3477-3480.

3. Yan S, Salley SO, Simon $\mathrm{Ng}$ (2009) Simultaneous transesterification and

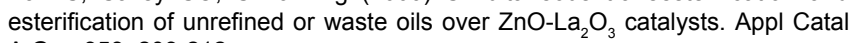
A Gen 353: 203-212.

4. Talebian-Kiakalaieh A, Amin NAS, Zarei A, Noshadi I (2013) Transesterification of waste cooking oil by heteropoly acid (HPA) catalyst: Optimization and kinetic model. Appl Energy 102: 283-292.

5. Corro G, Tellez N, Ayala E, Marinez-Ayala A (2010) Two-step biodiese production from Jatropha curcas crude oil using $\mathrm{SiO}_{2}$. HF solid catalyst for FFA esterification step. Fuel 89: 2815-2821.

6. Canakci M, Van Gerpen J (2001) Biodiesel production from oils and fats with high free fatty acids. Am Soc Agric Eng 44: 1429-1439.

7. Meher LC, Vidya Sagar D, Naik SN (2006) Technical aspects of biodiese production by transesterification- a review. Renew Sust Energ Rev 10: 248-268.

8. Encinar JM, González JF, Rodríguez-Reinares A (2007) Ethanolysis of used frying oil. Biodiesel preparation and characterization. Fuel Proc Techn 88: 513-522.

9. Vicente G, Martinez M, Aracil J (2004) Integrated biodiesel production: a comparison of different homogeneous catalysts systems. Bioresour Technol 92: 297-305. 
Citation: Manique MC, Lacerda LV, Alves AK, Bergmann CP (2018) Synthesis of Hydro-Sodalite as a Heterogeneous Catalyst for Reaction Kinetics of Soybean Oil Trans-Esterification. J Material Sci Eng 7: 500. doi: 10.4172/2169-0022.1000500

Page 6 of 6

10. Shu Q, Yang B, Yuan H, Qing S, Zhu G (2007) Synthesis of biodiesel from soybean oil and methanol catalyzed by zeolite beta modified with $\mathrm{La}^{3+}$. Catal Commun 8: 2159-2165.

11. Ramos MJ, Casas A, Rodríguez L, Romero R, Pérez A (2008)Transesterification of sunflower oil over zeolites using different metal loading: a case of leaching and agglomeration studies. Appl Catal A Gen 346: 79-85.

12. Carrero A, Vicente G, Rodríguez R, Linares M, del Peso GL (2011) Hierarchical zeolites as catalysts for biodiesel production from Nannochloropsis microalga oil. Catal Today 167: 148-153.

13. Beletskaya I, Tyurin V (2010) Recyclable nanostructured catalytic systems in modern environmentally friendly organic synthesis. Molecules 15: 4792-4814.

14. Liu B, Zhao Z (2007) Biodiesel production by direct methanolysis of oleaginous microbial biomass. J Chem Technol Biotechnol 82: 775-780.

15. Singh AK, Fernando AD (2007) Reaction kinetics of soybean oil transesterification using heterogeneous metal oxide catalysts. Chem Eng Technol 30: 1716-1720.

16. Izidoro JC, Fungaro DA, Santos FS, Wang S (2012) Characteristics of Brazilian coal fly ashes and their synthesized zeolites. Fuel Process Technol 97: 38-44.

17. Hartmann A, Petrov V, Buhl JC, Rübner K, Lindemann M, et al. (2014) Zeolite synthesis under insertion of silica rich filtration residues from industrial wastewater reconditioning. Adv Chem Eng Sci 4: 120-134.

18. Xie W, Huang X, Li H (2007) Soybean oil methyl esters preparation using NaX zeolites loaded with $\mathrm{KOH}$ as a heterogeneous catalyst. Bioresour Technol 98: 936-939.

19. Kusuma RI, Hadinoto JP, Ayucitra A, Soetaredjo FE, Ismadji S (2013) Natura zeolite from Pacitan Indonesia, as catalyst support for transesterification of palm oil. Appl Clay Sci 74: 121-126.

20. Manique MC, Lacerda LV, Alves AK, Bergmann CP (2017) Biodiesel production using coal fly ash-derived sodalite as a heterogeneous catalyst. Fuel 190: 268-273.

21. Freedman B, Butterfield RO, Pryde EH (1986) Transesterification kinetics of soybean oil. J Am Oil Chem Soc 63: 1375-1380.
22. Petkowicz DI, Rigo RT, Radtke C, Pergher SB, Santos JHZ (2008) Zeolite NaA from Brazilian chrysotile and rice husk. Microp Mesop Mater 116: 548-554

23. Harja M, Rusu L, Bucur D, Munteanu C, Ciocinta RC (2012) Fly ash-derived zeolites as adsorbents for Ni removal from waste water. Rev Roum Chim 57: 587-597.

24. Criado $M$, Fernández-Jiménez A, Palomo A (2007) Alkali activation of fly ash Effect of the $\mathrm{SiO}_{2} / \mathrm{Na}_{2} \mathrm{O}$ ratio. Part I: FTIR study. Microp Mesop Mater 106: 180-191.

25. Barthomeuf D (1996) Basic Zeolites: Characterization and uses in adsorption and catalysis. Catal Rev Sci Eng 38: 521-612.

26. Franus W, Wdowin M, Franus M (2014) Synthesis and characterization of zeolites prepared from industrial fly ash. Environ Monit Assess 186: 5721-5729.

27. Song C, Qi Y, Deng T, Hou X, Qin Z (2010) Kinetic model for the esterification of oleic acid catalyzed by zinc acetate in subcritical methanol. Renew Energy 35: 625-628.

28. Fauzi AHM, Amin NAS, Mat R (2014) Esterification of oleic acid to biodiese using magnetic ionic liquid: Multi-objective optimization and kinetic study. Appl Energy 114: 809-818.

29. Deshmane VG, Adewuyi YG (2013) Synthesis and kinetics of biodiese formation via calcium methoxide base catalyzed transesterification reaction in the absence and presence of ultrasound. Fuel 107: 474-482.

30. Singh AK, Fernando SD (2009) Preparation and reaction kinetics studies of $\mathrm{Na}$ based mixed metal oxide for transesterification. Energy Fuels 23: 5160-5164.

31. Dang TH, Chen BH, Lee DJ (2013) Application of kaolin-based catalysts in biodiesel production via transesterification of vegetable oils in excess methanol. Bioresour Technol 145: 175-181.

32. Kirumakki SR, Nagaraju N, Murthy KVVSBSR, Narayanan S (2002) Esterification of salicylic acid over zeolites using dimethyl carbonate. Appl Catal A Gen 226: 175-182. 